\title{
UN RELIEVE FUNERARIO HALLADO EN CONTRIBUTA IULIA UGULTUNIA
}

\section{A FUNERARY RELIEF FOUND AT CONTRIBUTA IULIA UGULTUNIA}

\author{
PEDRO MATEOS CRUZ* \\ ANTONIO PIZZO**
}

Resumen: Desde el año 2007 el Instituto de Arqueología de Mérida lleva a cabo un proyecto de investigación interdisciplinar en el yacimiento de Contributa Iulia Ugultunia, ciudad romana situada a pocos kilómetros de la población de Medina de las Torres, Badajoz. Dentro del solar en el que se sitúa el yacimiento, aunque fuera de sus murallas, en una zona documentada como posible área de necrópolis, apareció un fragmento de relieve funerario que es objeto de estudio a partir del análisis de su fisonomía originaria y de su iconografía. Palabras Clave: Roma, relieve funerario, monumento funerario, corona, Extremadura, Badajoz.

\section{INTRODUCCIÓN}

Los trabajos arqueológicos llevados a cabo por el Instituto de Arqueología de Mérida en el yacimiento de Contributa Iulia Ugultunia se iniciaron en 2007 con el desarrollo de las primeras prospecciones geofísicas en el solar conocido como "Los Cercos". Esta área fue adquirida recientemente por el Ayuntamiento de Medina de las Torres (Badajoz) para su documentación e investigación.

\footnotetext{
* Correo-e: p.mateos@iam.csic.es Instituto de Arqueología de Mérida, plaza de España 15, 06800-Mérida

** Correo-e: antoniopizzo@iam.csic.es Instituto de Arqueología de Mérida, plaza de España 15, 06800-Mérida
}

\begin{abstract}
From 2007 the Merida Institute on Archaeology has developed an interdisciplinary research project in the archaeological site of Contributa Iulia Ugultunia, a Roman town in the municipality of Medina de las Torres, Badajoz. Within a probable cemetery area outside the city walls, we reported the find of a fragment of a funerary relief, which is the subject of study through the analysis of its original physiognomy and iconography.
\end{abstract}

Key words: Roma, funerary relief, funerary monument, crown, Extremadura, Badajoz.

El interés por este yacimiento se remonta al siglo XIX, momento en el que J.A. Barrientos dirige los primeros trabajos arqueológicos realizados en el lugar para determinar la funcionalidad de los restos existentes y su posible vinculación con la antigua ciudad romana. Ya en el siglo XVII, Rodrigo Caro situaba Contributa Iulia en los límites de la actual ciudad de Fuente de Cantos y Tamayo de Salazar, años después, la localizaba, por primera vez, en Medina de las Torres. Las excavaciones posteriores practicadas por Barrientos no lograron definir de manera evidente el carácter de los restos pero supusieron la aparición de numerosas estructuras, togados y columnas que aumentaron el interés por el yacimiento (Mateos et al. 2009: 7-32). Dos siglos después, tras numerosas especulaciones sobre la vinculación de los restos con la mansio de Perceiana o con la antigua 


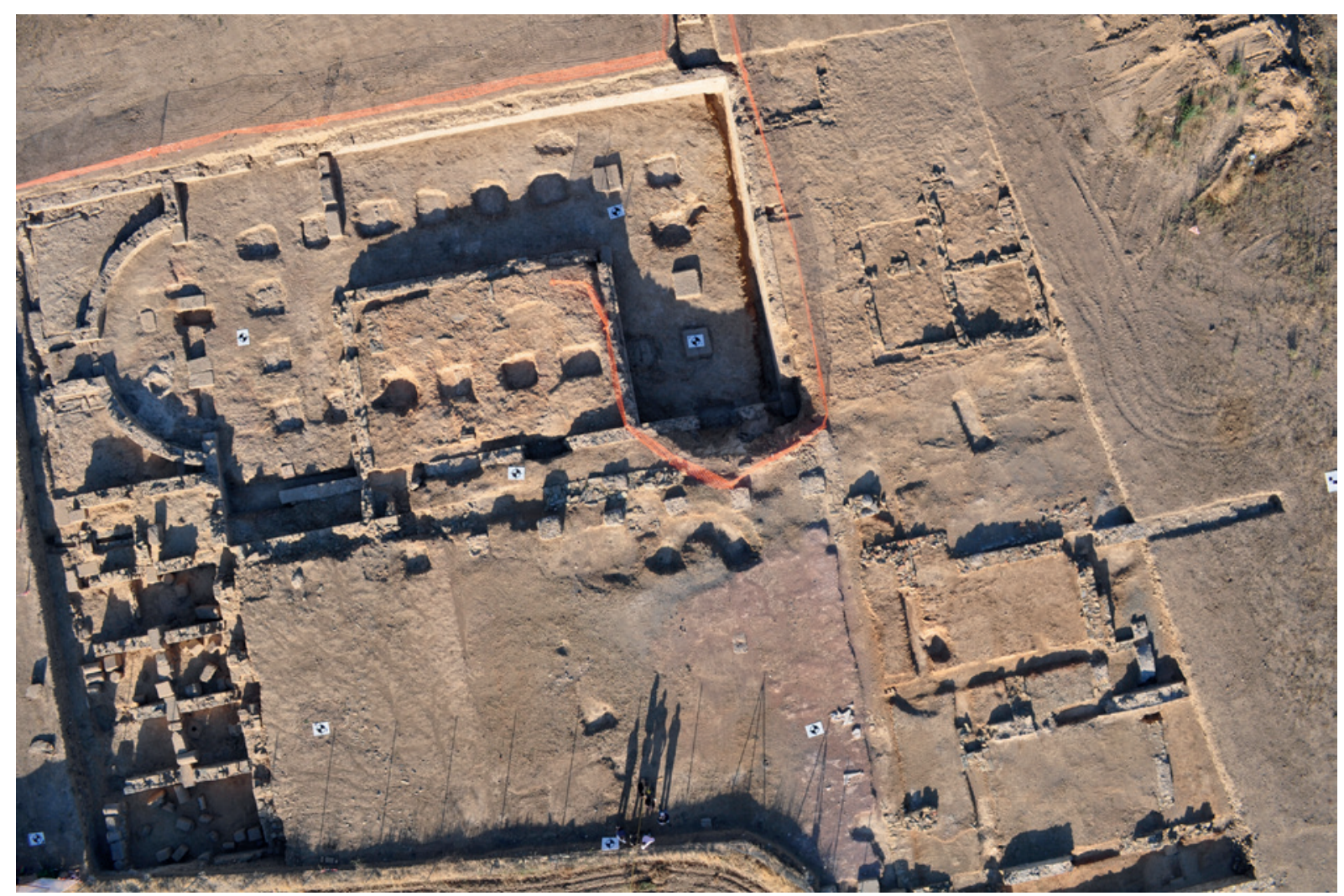

Figura 1. Vista aérea de las excavaciones arqueológicas desarrolladas en el área forense de la ciudad de Contributa Iulia.

ciudad de Contributa, han salido a la luz los primeros restos arqueológicos de la antigua ciudad. Hoy conocemos parte de su estructura urbana gracias al desarrollo de un proyecto de investigación denominado "Análisis urbanístico y territorial de la ciudad romana de Contributa Iulia" (PRI09B152) y financiado por la Consejería de Economía, Comercio e Innovación de la Junta de Extremadura entre 2009 y 2012. En buena medida, el conocimiento urbano ha evolucionado debido a los sucesivos trabajos arqueológicos llevados a cabo a través de dos Talleres de Empleo y a diversas campañas de excavaciones dirigidas desde el Instituto de Arqueología de Mérida. La continuidad de estas intervenciones ha permitido establecer una serie de elementos de reflexión sobre la tipología de los restos conservados y su inserción topográfica y urbanística.

Los primeros trabajos de prospección geofísica definieron la gran potencialidad arqueológica del solar de "Los Cercos"; del mismo modo, fue el inicio de un proyecto interdisciplinar de documentación, análisis e investigación por parte del Instituto de Arqueología que, a lo largo de los últimos años, ha desarrollado una gran actividad vinculada al yacimiento.
En la actualidad, podemos plantear una primera hipótesis de estructuración urbanística y evolución histórica del territorio circundante, gracias a la aplicación de diversas metodologías de prospección. Entre otras debemos destacar, por ejemplo, el uso de fotografías aéreas y la sucesiva interpretación de marcas en la vegetación mediante el análisis de fotografías ortorrectificadas. Estas actuaciones estaban ligadas a un plan global de prospecciones superficiales intensivas y otras prospecciones de carácter geofísico mediante la utilización del georradar, magnetómetro o resistivímetro. Algunos resultados y análisis de la metodología empleada han sido adelantados a la comunidad científica en diversas intervenciones realizadas con motivo de la celebración del VI Encuentro Peninsular de Arqueología del Suroeste organizado en Villafranca de los Barros (Badajoz) en el mes de octubre de 2012 (Mateos y Pizzo 2013: 1224-1258).

Los datos obtenidos en las excavaciones arqueológicas desarrolladas en el interior del perímetro urbano han hecho posible definir dos áreas importantes de la ciudad: por un lado, el área pública forense (fig. 1), localizada en la cima del cerro, en la que se han documentado 


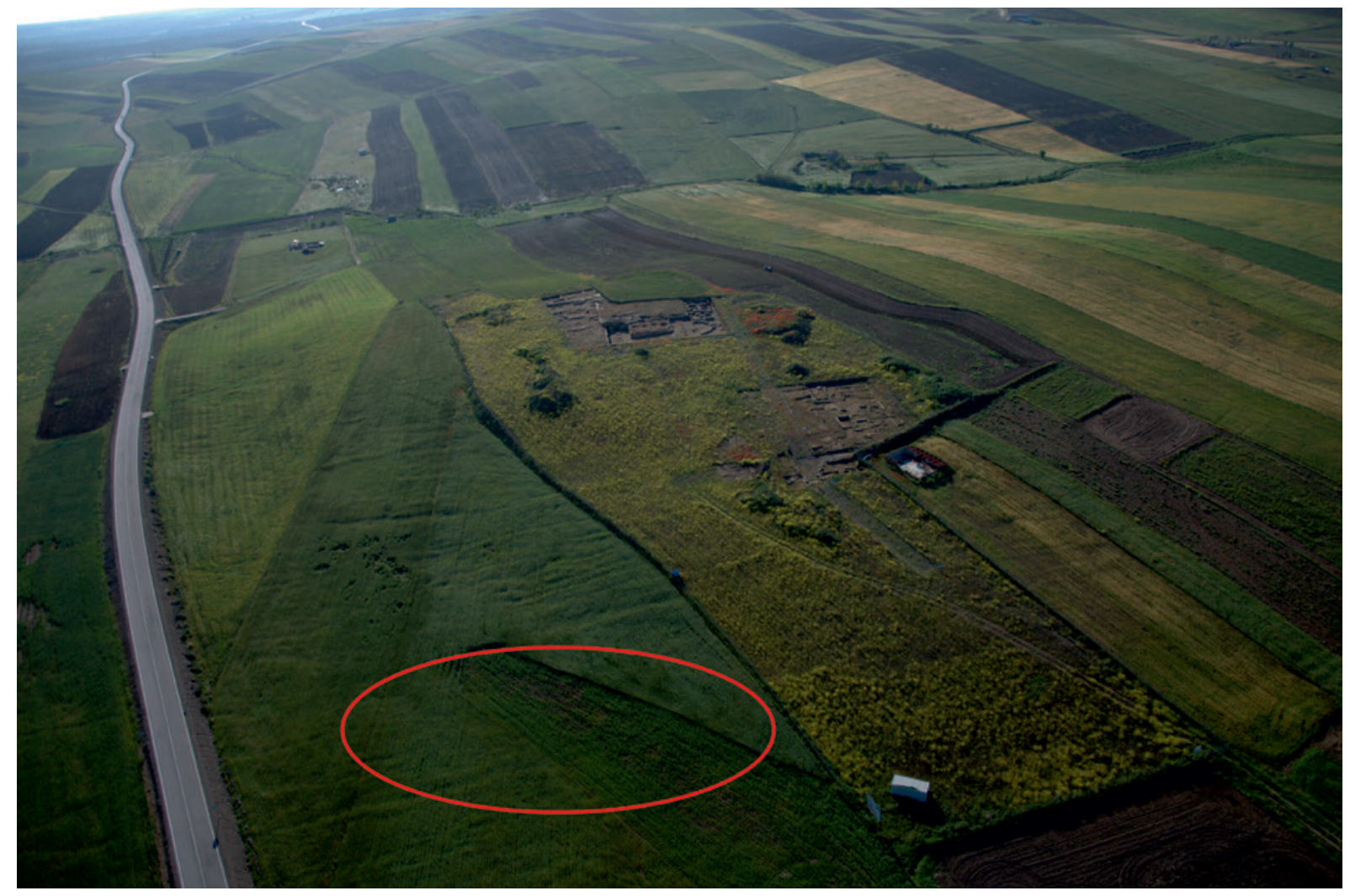

Figura 2. Vista aérea del yacimiento arqueológico de Contributa Iulia con indicación del lugar del hallazgo.

los principales edificios que componían el foro y sus diferentes etapas históricas; por otro, la puerta de acceso a la ciudad en el sector occidental, que ha permitido conocer las características y recorrido de un gran tramo de la cerca muraria, una manzana en la que se construyó un edificio con un probable uso comercial y un decumanus que, partiendo de la puerta de acceso, une ambas zonas desde la muralla al propio área forense (Mateos et al. 2009: 7-32, 2013, 1230).

A partir de todos estos trabajos se ha podido definir un recorrido hipotético del trazado de la muralla de la ciudad, así como el supuesto carácter de la ocupación del espacio extramuros. Así, mientras que en la zona meridional se documenta una intensa ocupación urbanística, en el lado oriental parece probable la existencia de edificios de carácter público. Por último, en el área de la muralla situada al oeste, podría situarse un espacio funerario ligado a diversas vías de acceso a la ciudad. La aparición de inscripciones funerarias, así como de algunos enterramientos confirma esta posibilidad. Es precisamente de esta última zona (fig. 2), de donde proviene un fragmento de relieve de tipo funerario que se encuentra actualmente en el Centro de
Interpretación del yacimiento que será objeto de estudio en este trabajo.

\section{DESCRIPCIÓN DEL RELIEVE}

El relieve está labrado en un bloque de caliza del que se conserva un fragmento informe cuyas dimensiones oscilan entre los $71 \mathrm{~cm}$ de altura máxima y $97 \mathrm{~cm}$ de longitud, con un grosor aproximado entre $24 \mathrm{~cm} \mathrm{y}$ $30 \mathrm{~cm}$. Del material se ha realizado un examen petrográfico de una muestra que se describe macroscópicamente como roca de composición carbonatada, masiva, constituida por un mosaico de granos de calcita. Posee color blanco con bandas grisáceas, de tamaño de grano fino. También se observa la presencia ocasional de juntas de presión-disolución o estilolitos.

La pieza presenta múltiples fracturas en sus lados izquierdo, superior e inferior, de modo que solo conserva intacto su canto derecho, que finaliza en una superficie abujardada, mientras que la zona trasera está simplemente desbastada ya que no estaría a la vista. El lado derecho muestra, en su parte alta, una moldura en resalte, 


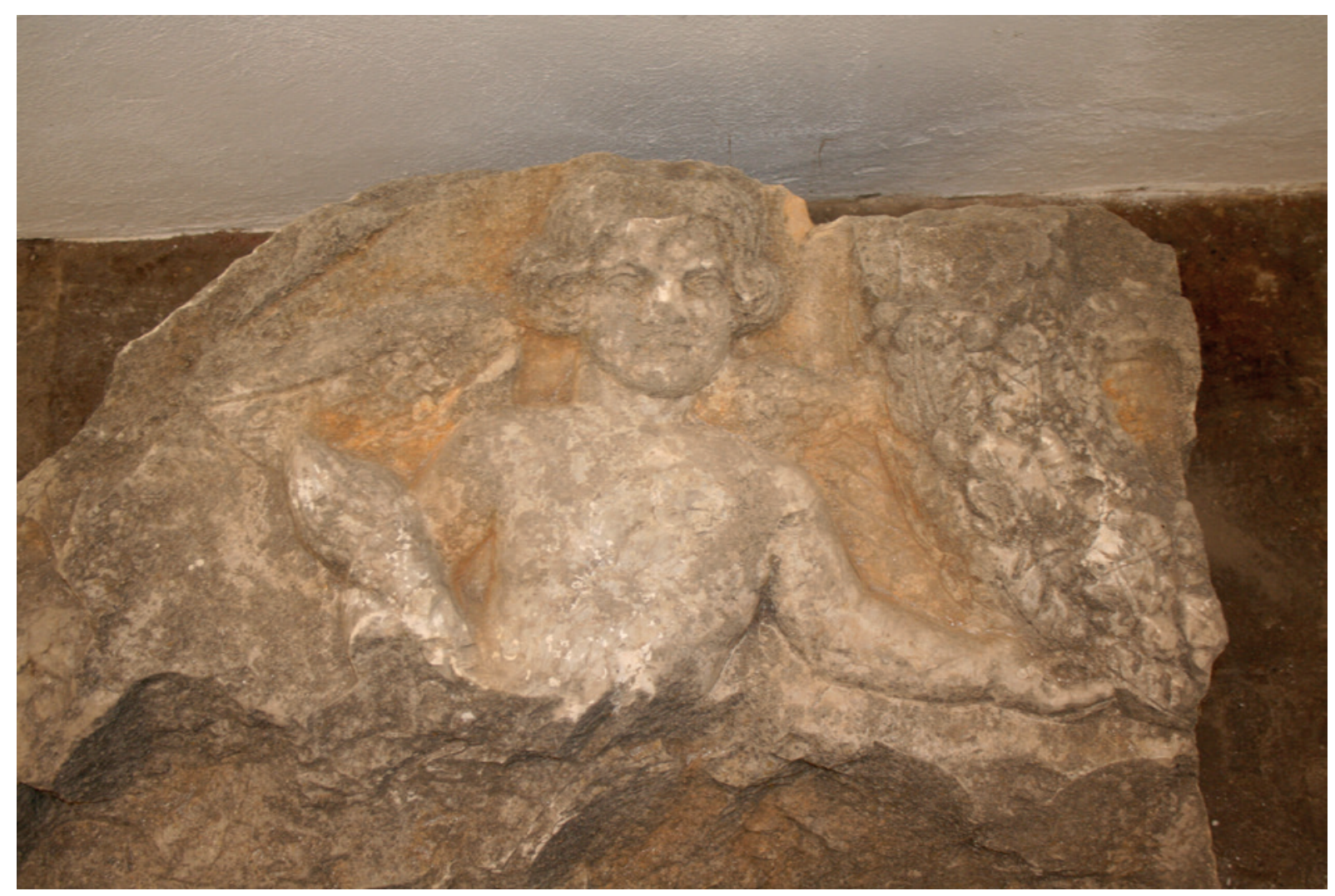

Figura 3. Vista frontal del relieve.

en forma de filete de perfil triangular que va desde el extremo derecho a la parte superior central de la pieza conformando una vertiente del triángulo que daría forma original al relieve. Dicha moldura acaba en el extremo derecho de la pieza, al finalizar la línea transversal, sin que se observe continuidad en el trazo vertical (fig. 3).

En el dorso lateral derecho se aprecian las huellas de dos grapas de sujeción. Ambas se sitúan en la zona superior del canto del lado derecho, que uniría ese mismo extremo con el eje triangular del relieve. La primera de ellas posee unas dimensiones aproximadas de $5,5 \mathrm{~cm}$ por $4,5 \mathrm{~cm}$ y es de planta cuadrangular. La segunda, también de forma rectangular, conserva unas medidas de $4 \mathrm{~cm}$ por $2,5 \mathrm{~cm}$ (fig. 4).

Es posible, por tanto, que se trate del lateral de un frontón de un monumento del que se conserva parte de su decoración formada por un erote alado en posición frontal y probablemente recostado que soporta en su mano izquierda una corona como elemento central del relieve y, en la derecha, una antorcha apoyada en el antebrazo. Del erote se puede contemplar con claridad la cabeza, las extremidades superiores, el tórax y las dos alas sobresaliendo de su espalda. La parte inferior no se conserva aunque se intuye un quiebro desde la cintura que sugiere que las piernas se extenderían hasta ocupar el extremo del frontón y, por tanto, la posición del erote sería un tanto recostada hacia la izquierda. En el extremo izquierdo del fragmento se representa el lado inferior derecho de un motivo floral. Resulta muy probable que se trate de una corona decorada con hojas de encina y frutos -bellotas- recogida con diversas taeniae de poca anchura y no de una guirnalda ya que, como se aprecia en el dibujo reconstructivo de la pieza y en el propio detalle fotográfico, la línea interior de carácter circular parece que se cierra, conformando un círculo más que una línea de tendencia abierta típica de una guirnalda (fig. 5).

En el interior de la probable corona se intuye la existencia del motivo que decoraría la parte central del frontón, del que se aprecia un trazo moldurado horizontal que parte del lado central de la corona y que se cruza con otro trazo, en vertical, proveniente del lado inferior.

Nada sabemos del motivo que decoraría la parte inferior central del relieve. Previsiblemente ese espacio podría estar ocupado por unas taeniae como sucede en numerosos relieves de carácter funerario. 
Figura 4. Vista lateral del fragmento de relieve en la que se aprecia un detalle de las huellas para las grapas de sujeción.
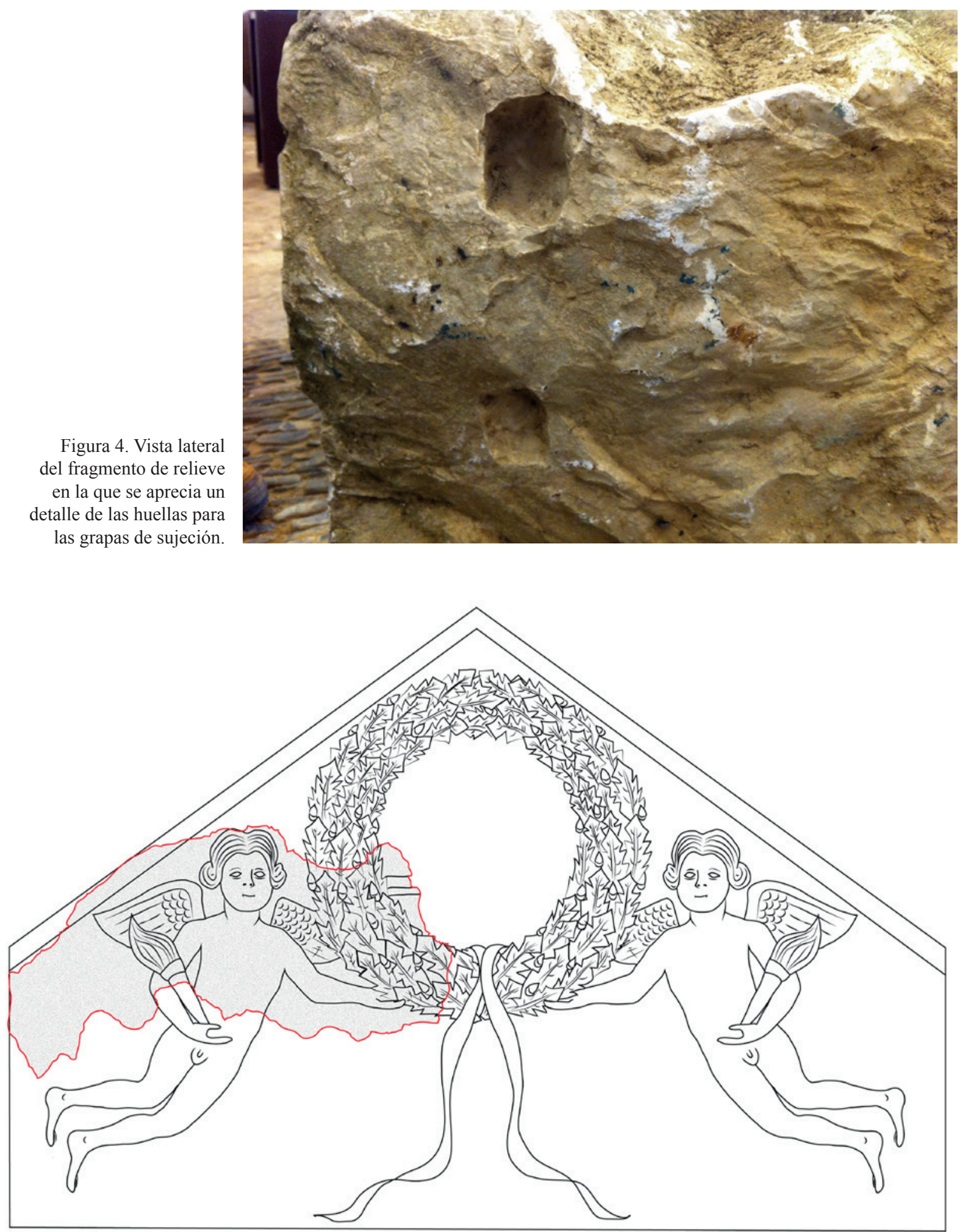

wำ

Figura 5. Reconstrucción ideal del relieve funerario (dibujo realizado por Valentín Jaramillo).

ISSN: 1133-4525 ISSN-e: 2255-3924 


\section{INTERPRETACIÓN COMO RELIEVE FUNERARIO}

La reconstrucción arquitectónica más plausible sugiere que la pieza formaría parte de un frontón triangular de aproximadamente $2,40 \mathrm{~m}$ de longitud y una altura máxima en el eje del triángulo de $1,60 \mathrm{~m}$. Los extremos del frontón presentan un final en ángulo recto que coincide con una terminación abujardada en su lado derecho, lo que plantea la posibilidad de que estuviera formando parte de una estructura de mayor tamaño. Las grapas situadas en el dorso del extremo derecho implican su ensamblaje con dicha estructura que, dada su naturaleza y su colocación en la parte superior de la fachada de un edificio, coincidiría con la cubierta de una construcción cuyas características arquitectónicas desconocemos.

Desde el punto de vista de la decoración y dada la simetría de los motivos que ornamentaban este tipo de elementos, parece lógico pensar que el frontón estaría compuesto por una corona central y dos erotes alados colocados a ambos lados, sujetando con una mano la láurea y con la otra una antorcha. Estos motivos emparentan la pieza con el mundo funerario.

En este tipo de monumentos, la corona posee una clara significación funeraria. El triunfo ante la muerte halla su mejor expresión en una imagen tomada de la vida: la corona recibida por los vencedores en los juegos (Cumont 1966: 432). Se trata de un motivo ornamental muy utilizado desde mediados del siglo I d.C. como símbolo de la superación de este mundo, tanto en la esfera civil como en la religiosa (Abad 1986: 128). Aparece representada mayoritariamente en aras, altares y templos. Del mismo modo que los clípeos y las conchas, las coronas aluden a un tipo de heroización del difunto, aunque a veces son sustituidas por una guirnalda semicircular dentro de la cual se incluye el retrato del propio difunto ya que este tipo de decoración es exclusivamente reservado al mundo funerario.

En nuestro caso, en el interior de la corona podría ir representado el retrato del difunto, la inscripción o cualquier otro motivo suficientemente representativo dado la importancia del lugar en el edificio. Así sucede con el frontón de un supuesto monumento funerario hallado en Coves de Vinromá (Castellón), en el que una corona de laurel ocupaba la parte central de la pieza y en su interior se realizó el retrato de un personaje masculino, probablemente el protagonista del monumento (Abad 1986: 119-136). En el lado contrario, debemos reseñar el motivo que ocupa el punto central de otro monumento funerario hallado en El Rompido (Huelva), aunque procedente de Mérida (Rodríguez 1973: 295310) cuya corona sepulcral está decorada en su interior simplemente por un motivo floral, una roseta de ocho pétalos que, en principio, resultaría poco significativo para el lugar que ocuparía en el monumento (fig. 6).

Nos encontramos, por tanto, ante un lateral de un frontón perteneciente a un monumento funerario difícil de precisar desde el punto de vista arquitectónico pero que, dadas sus reducidas dimensiones, podría relacionarse con un pequeño templete, posiblemente en forma de edícula, flanqueada por columnas.

Debemos desechar tanto su adscripción a otro tipo de edificio de mayor tamaño como su utilización formando parte de una estela o altar funerario finalizados en frontón, ya que las grapas halladas en el dorso derecho de la pieza señalan claramente que estaría incrustada en una estructura arquitectónica. A pesar de su semejanza con el frontón hallado en el monumento de Bitinia Severa en Budapest, debemos desechar su uso como remate de un encintado funerario, una especie de recinto abierto que rodearía la tumba de la difunta (Kremer 2006: 95) y que, en ocasiones, sirve como receptáculo para estelas, altares u otros monumentos (Facsady 2001: 131-137). A pesar de sus similitudes, no creemos que formara parte de la fachada de otro tipo de edificios de mayores dimensiones como frontón de un monumento, entre los que destaca el hallado en las proximidades de la villa de Fabara (Zaragoza). En este caso, se trata de un pequeño templo de planta rectangular muy poco acusada de 6,38 $\mathrm{m}$ por 7,34 m realizado en opera quadrata, levantado sobre podium, en el que se conserva la pieza central triangular del frontón situado en su fachada principal, de similares dimensiones a nuestro fragmento (Cancela 1982: 173-175). Aunque el edificio conserva dos inscripciones, una de ellas estaba grabada en el propio frontón y sobre él quedan las huellas del soporte de sujeción de las letras, cuya interpretación no deja lugar a dudas como $D($ is) M(anibus) (Puig y Cadafalch 1926: 89). También resulta interesante dentro de estos monumentos señalar el edificio funerario de los Atilii que, aunque de grandes dimensiones $(9,50 \mathrm{~m}$ por $5 \mathrm{~m}$ aproximadamente), posee semejanzas decorativas junto con el hallado en Chiprana, Zaragoza (Cancela 2001: 106) o el de Sagunto (Jiménez 1989: 207-220) con nuestro frontón. En el caso del mausoleo de los Atilii, se aprecia una sucesión de arcos bajo frontones arquitectónicos de similares dimensiones al nuestro. Dentro de las hornacinas se realizó una sucesión de guirnaldas de hojas de roble, con frutos y cintas (Cancela 2006: 213).

En la península ibérica conocemos, además, algunos otros ejemplos de edificios funerarios de gran tamaño 


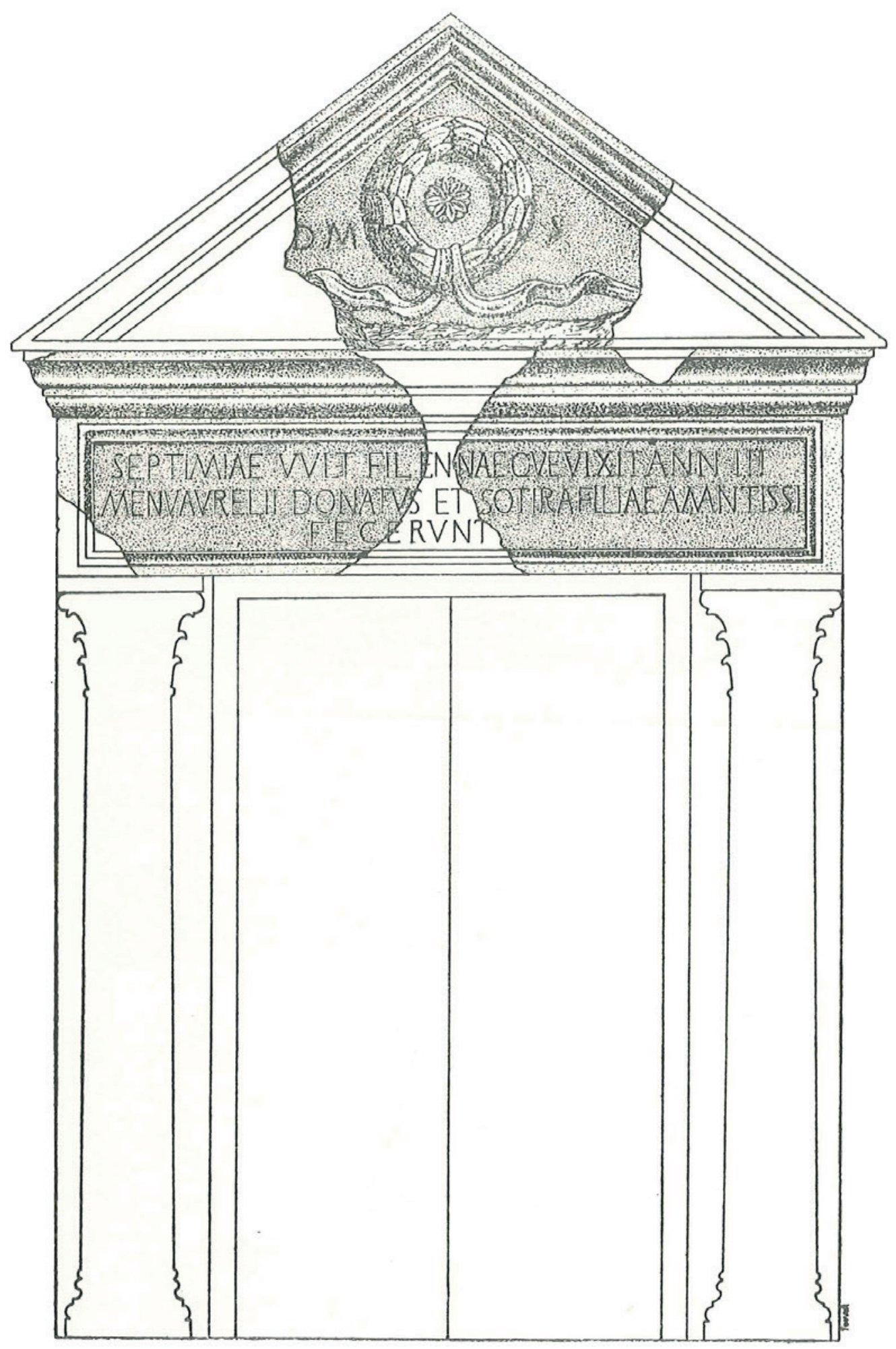

Figura 6. Relieve funerario hallado en El Rompido (Huelva) aunque procedente de Mérida (imagen tomada de Rodríguez y Chaves 1973: 296). 


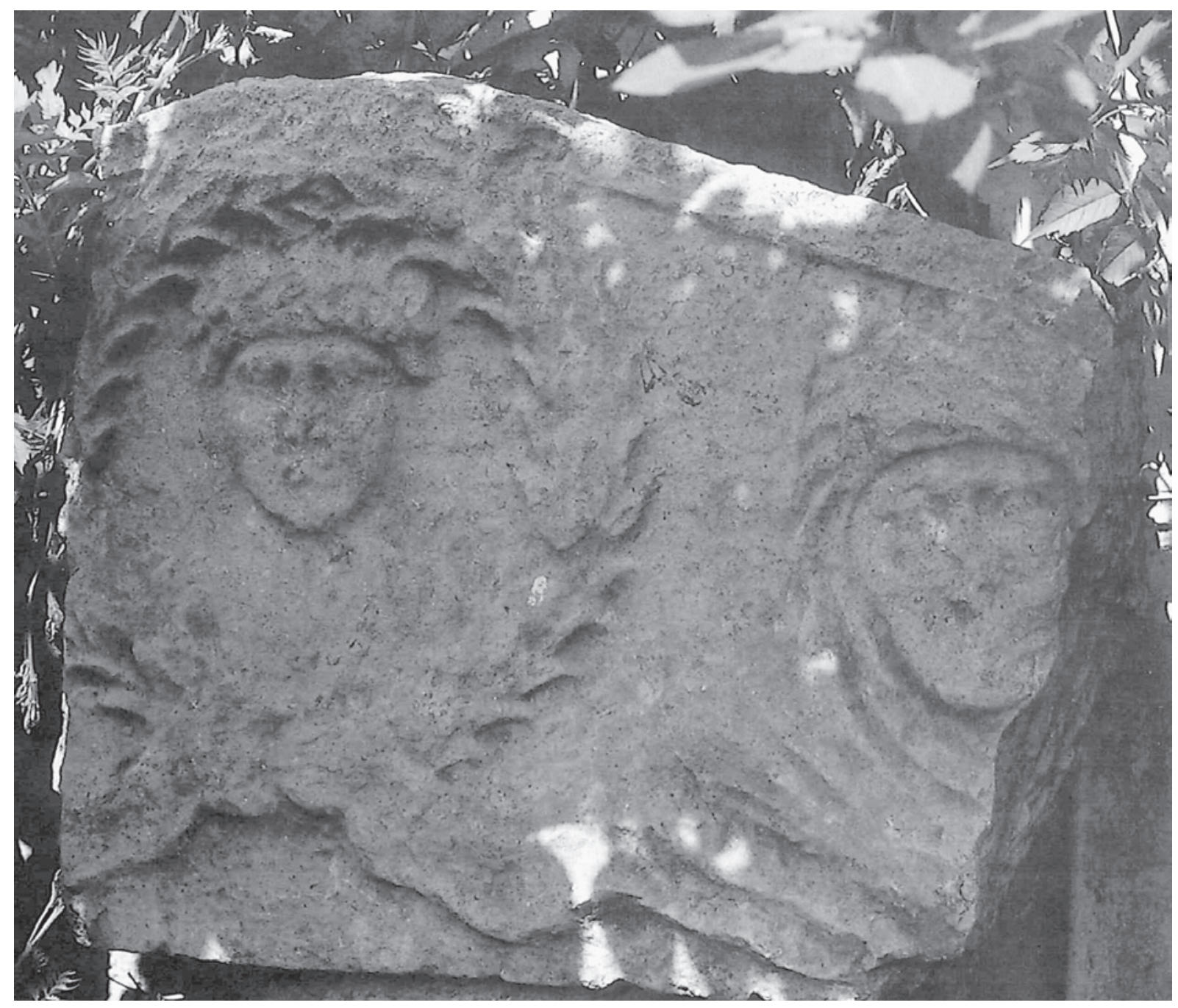

Figura 7. Fragmento de frontón procedente de Coves de Vinromá (Castellón) (imagen tomada de Abad 1986: 120).

(Beltrán 1990: 183-226, 2002: 233-258, Cancela 2002: 163-180). Los modelos que podemos encontrar aquí no son muy alejados de los habituales en las necrópolis itálicas o en provincias occidentales del mundo romano. Desde los primeros años de la conquista surgen enterramientos monumentales, en su mayoría de carácter familiar, de los que hoy queda constancia en ambientes rurales y en zonas de acceso a las ciudades (Cancela 2006: 205-219). Nos referimos a edificios de carácter turriforme de dimensiones similares al que podría acoger nuestro fragmento pero que, sin embargo, no suelen finalizar en frontón. Son los casos conocidos de la Torre de los Escipiones (Hauschild et al. 1966: 161188), Villajoyosa (Abad y Bendala 1985: 147-184), Almuñécar (Molina 1983: 275-279) o Clunia (Martín et al. 1993: 399-409).
En nuestro país no se han documentado, hasta el momento, monumentos funerarios con edícula que alberguen este tipo de frontones. Además de los dos fragmentos anteriormente comentados procedentes de Coves de Vinromá (fig. 7) y Mérida que podrían formar parte de un edificio similar en dimensiones y características al planteado para nuestro fragmento, conocemos otros de carácter turriforme abiertos con edícula que podrían asemejarse. Tal es el caso del edificio documentado en Vilablareix, Girona (Alberch 1989: 87-91) o la llamada "Torre del Cincho" en Carmona, Sevilla, (Rodríguez 1980: 425-435) si bien es probable que ambos edificios finalizaran en una cubierta piramidal y, por tanto, carente de frontones.

Fuera de nuestras fronteras se han documentado numerosos edificios, la mayoría con edícula, finalizados 


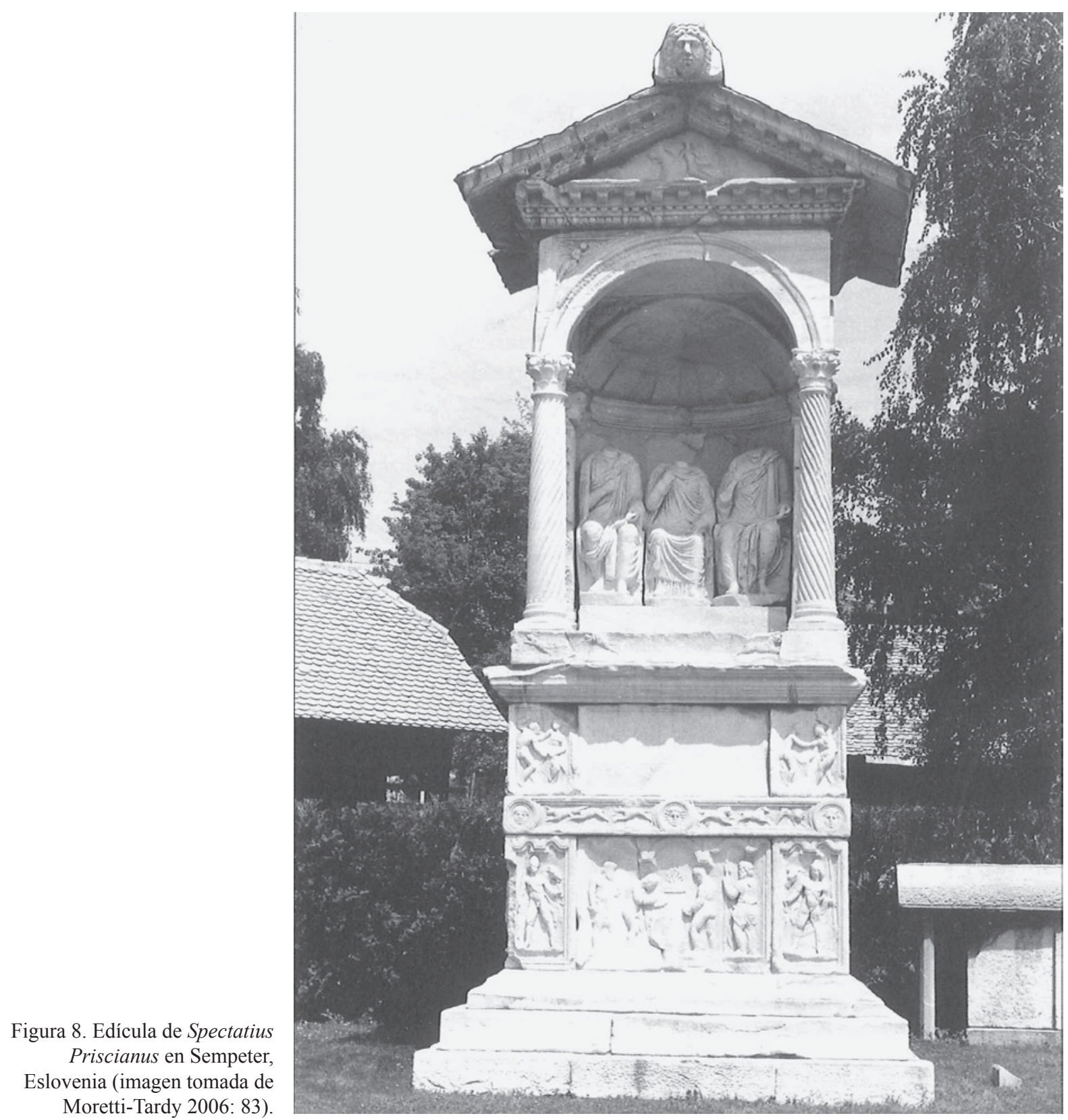

en frontón. Se trata de monumentos específicos que podrían no responder a los mismos criterios arquitectónicos que el nuestro pero que, indudablemente, guardan algún tipo de semejanza en cuanto a sus dimensiones, forma y funcionalidad. Edificios con edículas de carácter simple como, por ejemplo, el de Sempeter en Slovenia (Hesberg 1992: 158) o los ejemplares de Termessos o Haidra (Hesberg 1992: 127, 146 y 153) o edículas sobre podium con dos plantas soportadas con columnas como la de Porta Nocera en Pompeya
(Gabelmann 1979). También guardaría relación con la edícula finalizada en frontón decorado con una crátera hallada en Treviso (Tirelli 1997: 171).

En el caso de la ya citada edícula de Spectatius Priscianus en Sempeter el frontón respondería al mismo tipo que el nuestro, ya que se trata de un ejemplar de similares dimensiones (fig. 8), finalizando sus extremos en ángulos rectos e incrustados en una estructura de cubierta rematada en la fachada por una cornisa profusamente decorada (Kremer 2006: 83), al igual 
que la edícula funeraria de Bad Waltersdorf (Wedenig 1997: 232). Por último, reseñar el ejemplo del frontón de Tivoli, en la villa de Colle Tasso del que se conserva la mitad del remate de mármol que poseía una corona sepulcral en el centro y sendas inscripciones a los lados (Graen 2006: 275).

Todos estos edificios se encontraban coronados por un frontón decorado con diferentes motivos, aunque ninguno reproduce un elemento decorativo similar a nuestro fragmento en el que destaca como elemento central la corona sepulcral, con un motivo interior desconocido, flanqueada por dos erotes. Este detalle resulta muy recurrente como decoración en sarcófagos, altares, pulvinos o frisos de edificios funerarios y su posición depende de la forma del soporte o la geometría de la composición. Los erotes soportan guirnaldas, coronas, medallones, clípeos o cartelas y en función de la forma del soporte podrían aparecer de pie, volando o recostados (Espérandieu 1907: 355-357). El tema más repetido es la sucesión de erotes soportando esforzadamente una tira de guirnaldas como puede apreciarse en ejemplos de sarcófagos presentes en todo el mundo romano (Koch 1993), siendo muy habituales y bien analizados los ejemplos de Ostia (Herdejürgen 1990), Aquileia (Pochmarski 2009: 111119) o Afrodisias (Fahri 2007). Existen, además, numerosos casos de erotes alados llevando coronas o láureas, medallones, clípeos o conchas como motivo principal en la decoración, sobre todo, de sarcófagos (Koch y Sichtermann 1982). En España este tipo de motivos se repiten en algunos ejemplares del alto valle del Guadalquivir, como el ejemplar de Cástulo en el que el erote aparece desnudo, recostado, mirando al espectador y con su ala derecha extendida o el relieve localizado en la misma población del que se vislumbra el ala izquierda que posee la figura en su espalda (Baena y Beltrán 2002, nº 62 y 64 del catálogo, 103 y 104).

La corona es el elemento decorativo más usual en estos elementos funerarios aunque también suelen usarse en aras (Kockel 1983), altares y urnas funerarias (Altmann 1905) y, como hemos podido apreciar con anterioridad, también se conservan en algún frontón de edificio funerario, como el ejemplo procedente de Mérida con la roseta en su interior (Rodríguez y Chaves 1973: 295-310).

Más inusual resulta, como en nuestro caso, la aparición de los erotes portando con una de sus manos una antorcha. El uso de estas antorchas le da a la pieza un inequívoco carácter funerario (Stuveras 1969), como puede apreciarse en otros ejemplos como el sarcófago tarraconense de Santa Tecla (Clavería 2001: n 47), en el que dos erotes soportan con una mano una guirnalda y con la otra una antorcha encendida. El uso de la antorcha, como el de la cornucopia en las manos de los erotes, sugieren una derivación de modelos de arte romano más antiguo (Koch y Sichterman 1982: 48) aplicados también a sarcófagos provinciales posteriores, como ocurre en un ejemplar relacionado con los talleres de Campania del Museo del Sannio en Benevento (Herdejürgen 1993: 46) o en el caso de un sarcófago de Ostia, en el que dos erotes con una cornucopia en la mano soportan una corona con un retrato del matrimonio difunto (Zanker y Ewald 2003: 49).

\section{CONCLUSIONES}

El panorama comparativo del fragmento encontrado en Contributa resulta muy amplio y heterogéneo para establecer claramente la vinculación con un modelo escultórico y una cronología definida. Además, la modalidad del hallazgo del relieve, recuperado sin contexto arqueológico, vinculado exclusivamente a una posible zona de necrópolis cercana a la actual carretera de acceso a Medina de las Torres (Badajoz), imposibilita una conexión precisa con otros materiales o estructuras para su correcta datación.

Como se ha observado anteriormente, los elementos estilísticos procedentes del análisis comparativo con otros monumentos funerarios y la tipología de las decoraciones o motivos simbólicos existentes en el relieve, abren un arco cronológico muy amplio que poco ayuda a la definición de una fecha precisa para su construcción.

En el ámbito territorial del hallazgo se trata de una pieza muy original, sin apenas paralelos si se excluye el relieve antes citado procedente de Mérida, que constituye un elemento evidente de comparación con el fragmento de Contributa. En general, esta tipología de representaciones se ha localizado en la zona de Jaén y en la cuenca mediterránea, debido, en nuestra opinión, no solo al fenómeno histórico de especialización de talleres en esta zona sino también a un elemento historiográfico ligado con la atención prestada a estos argumentos con estudios en profundidad.

A pesar de la dificultad de individualizar las connotaciones estilísticas y cronológicas precisas con respecto a los contextos conocidos, es posible aportar nuevos elementos de carácter histórico sobre la producción de estos relieves en un ámbito geográfico desvinculado, hasta la actualidad, de los grandes circuitos relacionados con materiales de esta tipología.

La procedencia del soporte lapídeo del relieve abre, en términos generales, cuestiones distintas vinculadas 


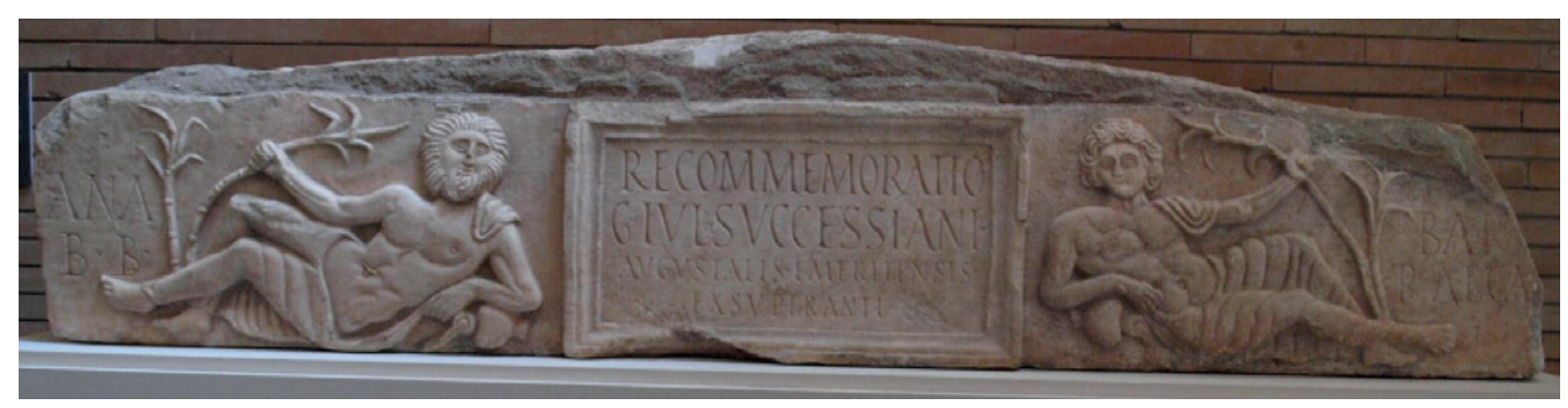

Figura 9. Relieve del dintel emeritense que representa los ríos Anas y Barraeca.

con las relaciones económicas de la ciudad romana de Contributa. La peculiaridad del relieve en esta zona podría indicar una posible relación comercial con otras ciudades de la Bética que facilitarían la llegada de estos productos en el noroeste de la región.

Sin embargo, nuestra aportación al conocimiento de estas producciones escultóricas radica en la posibilidad de afirmar la presencia de un taller local en la misma ciudad. El análisis arqueométrico del soporte lapídeo indica, claramente, la explotación de rocas locales de Alconera, situado a $10 \mathrm{~km}$ del yacimiento de Contributa. En este sentido, es posible adscribir el modelo estilístico de nuestro fragmento al citado relieve procedente de Mérida, con una producción en Contributa o en las cercanías de las canteras de Alconera que distribuye estos productos en una porción amplia de territorio.

La presencia de este taller local complica la definición cronológica de la pieza, debido a la imposibilidad de descifrar con un solo fragmento sin contexto estratigráfico, las modalidades de trasmisión de eventuales modelos. Los rasgos estilísticos del tratamiento del cabello del erote, comparables con figuras cuya adscripción cronológica parece relacionada con producciones de mediados del siglo III, como por ejemplo en el relieve del dintel emeritense que representa los ríos Anas y Barraeca (Canto et al. 1997: 247-294), no ayudan a establecer directamente una conexión cronológica (fig. 9). Es probable que la adquisición de determinadas referencias estilísticas se haya producido en el taller de Contributa en épocas anteriores y procedentes de otros ámbitos territoriales de la misma Bética.

A pesar de esta dificultad para encontrar una referencia cronológica precisa, nos parece de gran interés la posibilidad de plantear, por primera vez, la presencia de un taller escultórico en esta ciudad, atribuyendo un nuevo papel productivo a un ámbito de objetos tradicionalmente vinculados con otras áreas regionales.

\section{Agradecimientos}

Nuestro agradecimiento a María Isabel Mota, del centro tecnológico Intromac, por la colaboración en el análisis petrográfico de una muestra del relieve cuyos resultados arqueométricos específicos se publicarán próximamente.

\section{BIBLIOGRAFÍA}

Abad Casal, L. (1986): "El relieve romano de Coves de Vinromá (Castellón)”. Lucentum 5: 119-136.

Abad, L. y Bendala, M. (1985): "Los sepulcros turriformes de Daimuz y Villajoyosa: dos monumentos romanos olvidados". Lucentum 4: 147-184.

Alberch, X. (1989): "Elements pel coneixement de la vil.la romana de Vilablareix". Cypsela 7: 87-91.

Altmann, W. (1905): Römische Grabaltäre der Kaiserzeit. Berlín, Weidmann.

Baena, L. y Beltrán, J. (2002): Esculturas romanas de la provincia de Jaén, Corpus signorum Imperii romani, T. 1, V. 2. Murcia, Editorial Tabularium.

Beltrán, J. (1990): "Mausoleos romanos en forma de altar del Sur de la Península Ibérica". Archivo Español de Arqueología 63: 183-226.

Beltrán, J. (2002): "La arquitectura funeraria de Hispania meridional", en D. Vaquerizo (ed.), Espacios y usos funerarios en el occidente romano: 233-258. Córdoba, Universidad de Córdoba.

Cancela, M.L. (1982): "Fabara, avance de una excavación". Boletín del Museo de Zaragoza 1: 173-175.

Cancela, M.L. (2001): "Los monumentos funerarios de las élites locales hispanas”. Élites hispaniques, Études 6: 106.

Cancela, M.L. (2006): "Los monumentos funerarios hispanos", en D. Tardy et J. C. Moretti (eds.), L'architecture funeraire monumentale. La Gaule 
dans L'Empire Romain: 205-219. París, Commitée Des Travaux Historiques et scientifiques.

Canto, A.; Bejarano, A. y Palma, F. (1997): “ El mausoleo del dintel de los ríos de Mérida, Revve Anabaraecus y el culto a la confluencia ". Madrider Mitteilungen 38: 247-294.

Clavería, M. (2001): Los sarcófagos romanos de Cataluña. V.I. Barcelona, Editorial Tabularium

Cumont, F. (1966): Recherches sur le symbolisme funéraire des romains. París, Editorial Geuthner.

Espérandieu, E. (1907): Recuil Général des bas-reliefs de la Gaule romaine, I. París, Imprente Nationale

Facsady, A. (2001): Die Maastrichter Akten des 5 internationalen Kolloquiums über das provinzialrömische Kunstschaffen: 131-137. Maastricht, Stichting Willem Goossens.

Fahri, I. (2007): Girlanden-Sarkophage aus Aphrodisias. Mainz am Rheim, Ph. von Zabern.

Gabelmann, H. (1979): Römische Grabbauten der frühen Kaiserzeit. Sttutgart, Frühgeschichte in Württemberg und Hohenzollern.

Graen, D. (2006): Sepultus in villa. Die Grabbauten Römischer Villenbesitzer. Hamburgo, Dr. Kovač.

Hauschild, T.; Mariner, S. y Niemeyer, H.G. (1966): "Torre de los Escipiones - Ein römischer Grabturm bei Tarragona”. Madrider Mitteilungen 7: 161-188.

Herdejürgen, H. (1990): "Girlandensarkophage aus Ostia”, en M. True, G. Koch (eds.), Roman funerary monuments in the Paul Getty Museum: 95-114. Los Ángeles, J.P. Getty Museum.

Hesberg, H. (1992): Römische Grabbauten. Roma, Wissenschaftliche Buchgesellschaft.

Jiménez Salvador, J. L. (1989): "El monumento funerario de los Sergii en Sagunto", Homenatge A. Chabret, 1888-1988: 207-220. Valencia, Generalitat Valenciana.

Kremer-Molitor, G. (2006): 'L'architecture funeraire monumentales dans le Norique, la Pannonie et la Dacie", en D. Tardy, J.C. Moretti (eds.), L'architecture funeraire monumentale. La Gaule dans L'Empire Romain: 79-96. París, Comite Des Travaux Historiques Et scientifiques.

Koch, G. (1993): Sarkofage der römischen Kaiserzeit. München, Wiss. Buchges.

Koch, G. y Sichtermann, H. (1982): Römische sarkophage. Handbuch der Archäologie. Munich, Beck.

Kockel, V. (1983): Die Grabbauten vor dem Herculaner Tor in Pompeii. Mainz, Ph. von Zabern.
Martín Bueno, M. y Cancela, M. L. (1993): "Hispanie romaine: architecture funéraire monumentale dans le monde rural", en A. Ferdière (ed.), Monde des morts, monde des vivants en Gaule rurale, Actas du colloque Archea-Ager: 399-409. Orleans, Feracf/La Simarre.

Mateos, P.; Pizzo, A. y Delgado, P. (2009): “¿Contributa Iulia Ugultunia?, Intervenciones arqueológicas en el yacimiento arqueológico de "Los Cercos" en Medina de las Torres (Badajoz)". Romula 8: 7-32.

Mateos, P. y Pizzo, A. (2013): "Primeros datos acerca de la topografía y el urbanismo de Contributa Iulia (Medina de las Torres, Badajoz)", en Actas del VI Encuentro de Arqueología del Suroeste Peninsular: 1225-1258. Mérida, CSIC.

Molina, F. (1983): Almuñecar: Arqueología e Historia: 275-279. Granada, Diputación Provincial de Granada.

Moretti, J.C. y Tardy, D. (eds.) (2006): L'architecture funéraire monumentale: la Gaule dans l'Empire romain, Actes du colloque organisé par l'IRAA du CNRS et le Musée Archéologique Henri-Prades. Lattes (11-13 octubre 2001). París, Commitée des Travaux Historiques et Scientifiques.

Pochmarski, E. (2009): "Die girlandentragenden Eroten von forum in Aquileia. Reliefs Zwischen der stadtrömischen und der provinzialrömischen kunst", en T. Nogales e I. Rodá (eds), Roma y las Provincias, modelo y difusión, V.I: 111-119. Roma, L'Erma di Bretschneider.

Puig y Cadafalch, J. (1926): "El sepulcre de Lucius Emilius Lupus de Fabara". Anuari Institut d'Estudis Catalans: 89.

Rodríguez Hidalgo, J. M. (1980): “Anotaciones en torno a Basilippo. La Torre de Cincho". Habis 1011: 425-435.

Rodríguez Neila, J.F. y Chaves, F. (1973): "Un monumento funerario procedente de Emerita". Habis 4: 295-310.

Stuveras, R. (1969): Le putto dans l'art romain. Bruselas, Latomus.

Tirelli, M. (1997): “Appunto sulle necropole di Tarvisium et Iulia Concordia", en M. Mirabella Roberto (ed.), Monumenti sepulcrali romani in Aquileia e nella Cisalpina: 169-173. Aquileia, Editreg.

Wedenig, R. (1997): Epigraphische Quellen zur städtischen Administration in Noricum: 205-245. Graz, Geschichtsverein für Kärnten.

Zanker, P. y Ewald, B. C. (2003): Mit Mythen leben. Die Bilderwelt der römischen sarcophagi 49: 159180. Munich, Hirmer. 